\title{
SISTEM INFORMASI BERBASIS WEB PADA PROGRAM STUDI HUBUNGAN INTERNASIONAL UNIVERSITAS MATARAM MENGGUNAKAN CONTENT MANAGEMENT SYSTEM
}

\author{
(WEB-Based Information System in Department Of International Relations Mataram \\ University using Content Management System)
}

Muhammad Afif Ma'ruf ${ }^{[1]}$, Nadiyasari Agitha ${ }^{[1]}$, Mala Mardialina ${ }^{[2]}$
${ }^{[1]}$ Dept. Informatics Engineering, Mataram University
J1. Majapahit 62, Mataram, Lombok NTB, Indonesia
${ }^{[2]}$ Dept. International Relations, Mataram University
J1. Majapahit 62, Mataram, Lombok NTB, Indonesia
Email: afif23ixa@gmail.com; [nadiya, mala.mardialina]@unram.ac.id

\begin{abstract}
Abstrak
Perkembangan teknologi saat ini semakin pesat, terutama dalam bidang pendidikan. Pendidikan merupakan salah satu bidang yang perkembangan teknologinya berkembang pesat sehingga dibutuhkan sistem komputerisasi yang tepat. Website Prodi Hubungan Internasional merupakan sistem informasi seputar akademik dan kemahasiswaaan, website ini masih memiliki kekurangan dalam memberikan informasi dan pengalaman pengguna dalam mengakses fitur yang diinginkan, sehingga perlu dikembangkan untuk mencapai proses penyebaran informasi yang baik dengan didukung pemahaman dari mahasiswa dan dosen selaku pengguna dan pengelola website. Oleh karena itu pada pengabdian masyarakat ini dilakukan pengembangan website dengan menggunakan CMS dan dilakukan analisis User Center Design untuk mendapatkan website dengan fitur yang mudah digunakan oleh pengguna. Hasil yang didapatkan dari pengujian pada mahasiswa dan admin program studi Hubungan internasional Universitas Mataram dengan menggunakan Mean Opinion Score yaitu sebesar $89.74 \%$ responden setuju bahwa pengembangan sistem informasi yang dibuat dapat membantu memberikan informasi lebih baik dari sebelumnya.
\end{abstract}

Keywords: Sistem Informasi, Metode User Center Design, Teknologi Informasi, Website, Content Management System.

\subsection{Latar Belakang}

\section{Pendahuluan}

Pada saat ini perkembangan ilmu dan teknologi semakin pesat, khususnya teknologi informasi dan telekomunikasi yang memberikan peranan penting dalam kehidupan manusia dalam banyak bidang. Menurut $\mathrm{H}$. Hamzah B. uno mengatakan bahwa kecenderungan pendidikan di Indonesia di masa mendatang adalah sebagai berikut [1] :

1. Berkembangnya pendidikan terbuka dengan modus belajar jarak jauh (distance learning). Kemudian untuk menyelenggarakan pendidikan terbuka dan jarak jauh perlu dimasukkan sebagai strategi utama.

2. Sharing resource bersama antar lembaga pendidikan/latihan dalam sebuah jaringan perpustakaan dan instrumen pendidikan lainnya (guru, laboratorium) berubah fungsi menjadi sumber informasi daripada sekedar rak buku.

Kampus Universitas Mataram lebih khususnya Program Studi (Prodi) Hubungan Internasional Universitas Mataram (HI UNRAM) sedang mengembangkan sistem komputerisasi yang baik. Website yang dikembangkan berupa sistem informasi Prodi HI seperti berita seputar akademik dan kemahasiswaan. Pengembangan website tersebut menggunakan wordpress sebagai platformnya. Wordpress memungkinkan pengguna tidak perlu untuk melakukan instalasi atau konfigurasi yang cukup sulit. Fitur - fitur yang dimiliki oleh wordpress cukup lengkap.

Program Studi HI ingin mengembangkan website tersebut dengan memperbaiki fitur serta tampilantampilannya untuk memberikan informasi yang lebih mudah diakses oleh mahasiswa, dosen, staf dan pengguna lain yang mengunjungi website tersebut, namun karena pengelola masih kurang mengetahui cara memperbaiki halaman website agar sesuai dengan yang diinginkan, sehingga pengembangan website menjadi terhambat.

Oleh karena itu perlu diadakannya sosialisasi untuk membantu pengembangan website Program Studi Hubungan Internasional agar kedepannya dapat dikelola dengan staf yang kompeten dan dilakukan pengembangan website sesuai dengan analisis pengembangan metode User Center Design untuk mendapatkan website dengan pengguna sebagi pusat dari perkembangan sistem informasi dalam hal ini adalah Program Studi Hubungan Internasional. 


\subsection{Tujuan dan Manfaat}

a. Tujuan.

Tujuan pengabdian masyarakat yang dilakukan di Program Studi Hubungan Internasional Universitas Mataram antara lain sebagai berikut :

1. Mengembangkan website menggunakan analisis User Center Design (UCD) untuk menghasilkan website dengan pengguna sebagai pusat dari pengembangan sistem,

2. Memberikan sosialisasi dan pelatihan kepada mahasiswa dan dosen Prodi Hubungan Internasional Universitas Mataram.

b. Manfaat.

Dalam pengabdian masyarakat ini terdapat beberapa manfaat penting bagi mahasiswa, program studi maupun instansi tempat dilaksanakannya pengabdian masyarakat antara lain:

1. Bagi mahasiswa

a) Menambah pengetahuan dan pengalaman mahasiswa mengenai kondisi lapangan yang sebenarnya,

b) Mahasiswa dapat mengimplementasikan materi perkuliahan ke dalam pengabdian masyarakat ini,

c) Mengetahui sejauh mana kemampuan mahasiswa menerapkan ilmunya yang telah didapatkan.

d) Mendapatkan teknis bagaimana mengembangkan website.

2. Bagi Program Studi Hubungan Internasional

a) Membantu instansi dalam pengembangan website sesuai dengan kesepakatan.

b) Mendapatkan pemahaman terkait cara mengambangkan dan mengelola website.

\section{Tinjauan Pustaka}

\section{$2.1 \quad$ Internet}

Internet adalah jaringan global yang menghubungkan komputer di seluruh dunia. Dengan internet, sebuah komputer bisa mengakses data yang terdapat pada komputer lain di benua yang berbeda. Sebuah toko online bisa tetap terbuka selama 24 jam sehari dan 7 hari seminggu tanpa henti. Dengan internet, kejadian penting yang terjadi di suatu negara bisa segera diketahui oleh orang lain di negara yang berbeda [2].

\subsection{Content Management System (CMS)}

CMS atau Content Management System adalah perangkat lunak yang memungkinkan untuk menambah dan memanipulasi (mengubah) isi dari suatu situs web. Dengan demikian setiap orang penulis maupun editor, setiap saat dapat menggunkan secara leluasa untuk membuat, menghapus atau bahkan memperbaharui isi website tanpa campurtangan langsung dari pihak webmaster [3].

CMS yang banyak digunakan saat ini adalah server CMS (WCMS). WCMS adalah perangkat lunak yang berfungsi untuk membangun dan memelihara/updating web, yang dirancang sedemikian rupa sehingga proses pembuatan dan pemeliharaan web lebih mudah, efektif, baik bagi orang yang mengerti teknologi maupun yang tidak [4].

\subsection{Sistem Informasi}

Sistem informasi adalah suatu sistem dalam suatu organisasi yang mempertemukan kebutuhan pengolahan transaksi harian yang mendukung fungsi operasi organisasi yang bersifat manajerial dengan kegiatan strategi dari suatu organisasi untuk dapat menyediakan kepada pihak luar tertentu dengan informasi yang diperlukan untuk pengambilan keputusan [5].

Menurut Whitten, Bentley, dan Ditman sistem informasi adalah pengaturan orang, data, proses, dan informasi (TI) atau teknologi informasi yang berinteraksi untuk mengumpulkan, memproses, menyimpan, dan menyediakan sebagai output informasi yang diperlukan untuk mendukung sebuah intansi atau organisasi [6].

\subsection{User Center Design (UCD)}

User Centered Design (UCD) merupakan paradigma baru dalam pengembangan sistem berbasis web. Konsep dari UCD adalah pengguna sebagai pusat dari proses pengembangan sistem, dan tujuan/sifat-sifat, konteks serta lingkungan sistem semua didasarkan dari pengalaman pengguna. Tujuan dilakukan pendekatan UCD adalah untuk menghasilkan produk dengan nilai usability yang tinggi [7].

Terdapat empat proses dalam UCD, yakni sebagai berikut [8].

a. Memahami dan Menentukan Konteks Pengguna (Specify Context of Use): Proses ini membutuhkan pemahaman tentang tujuan penggunaan sistem, karakteristik pengguna, lingkungan tempat pengguna akan menggunakan sistem, dan penentuan kebutuhan minimal dan optimal sistem. 
b. Menentukan Kebutuhan Pengguna dan Organisasi (Specify User and Organizational Requirements): Dalam proses ini dibuat penyataan eksplisit tentang kebutuhan pengguna dan organisasi dalam hubungannya dengan konteks deskripsi pengguna.

c. Solusi Perencanaan yang Dihasilkan (Produce Design Solution): Membuat simulasi atau prototipe sebagai solusi konkret, serta memperlihatkan dan melakukan ujicoba solusi tersebut kepada pengguna. Setelah uji coba dilakukan, umpan balik dari pengguna digunakan untuk memperbaiki rancangan solusi dan jika diperlukan proses ini diulangi sampai dengan tujuan perancangan terpenuhi.

d. Evaluasi Perancangan Terhadap Kebutuhan Pengguna (Evaluate Designs Against User): Evaluasi dilakukan secara formative, yaitu dengan menyediakan umpan balik yang akan digunakan untuk memperbaiki rancangan dan summative, yaitu dengan melakukan penilaian, tujuan pengguna dan organisasi telah tercapai atau belum.

\subsection{WEBUSE}

Website Usability Evaluation (WEBUSE) berfokus pada pengembangan sistem evaluasi usability berbasis web dengan pendekatan tindakan subyektif yang melibatkan partisipasi dari pengguna untuk memberikan penilaian pada sebuah website. Pengembangan pendekatan WEBUSE sebagai standar pengukuran usability, dengan metode evaluasi kuisoner berbasis web yang memungkinkan pengguna untuk menilai usability dari website yang akan dievaluasi [9].

\subsection{Mean Opinion Score}

Pengujian MOS (Mean Opinion Score) digunakan untuk mengetahui respon penilaian secara subjektif dari responden terhadap sistem yang dibuat berdasarkan pengamatan hasil survey [10].

\section{Metode Pengabdian Masyarakat}

Metode pelaksanaan dari kegiatan pengabdian ini digambarkan pada diagram alir Gambar 1

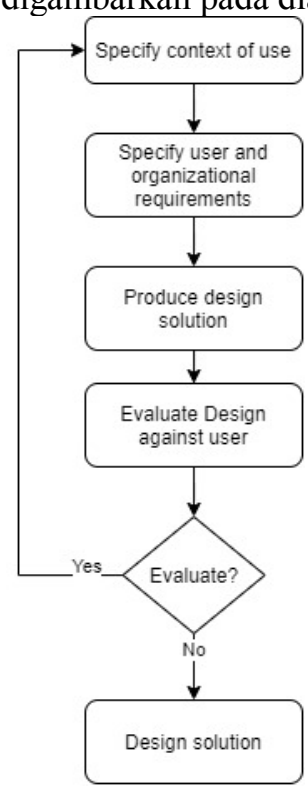

Gambar 1. Diagram alir metode pelaksanaan pengabdian masyarakat.

\subsection{Menentukan Konteks Pengguna (Specify Context of Use)}

Sistem informasi website Hubungan Internasional yang akan dikembangkan merupakan aplikasi berbasis $w e b$. Identifikasi pengguna dilakukan dengan melakukan diskusi dengan pihak Hubungan Internasional dalam hal ini dosen pembimbing lapangan yang ditunjuk selaku pembimbing praktik kerja lapangan untuk memberi gambaran pengembangan sistem yang akan dibangun dan menjelaskan fitur - fiturnya. Target yang ingin dicapai dari hasil konteks pengguna oleh Hubungan Internasional adalah pengunjung dan admin. 


\subsection{Menentukan Kebutuhan Pengguna dan Organisasi (Specify User and Organizational Requirements)}

Pada tahap ini akan dilakukan identifikasi terhadap kebutuhan sistem informasi Hubungan Internasional untuk keperluan menyebarluaskan informasi dari prodi Hubungan Internasional yaitu mahasiswa, dosen dan pihak diluar kampus. Analisis pengembangan website akan dilakukan dengan meninjau dua aktor sesuai dengan konteks yang telah dibuat yaitu dari segi kebutuhan pengunjung dan segi kebutuhan admin.

\subsubsection{Analisa Kebutuhan Pengguna}

a. Pengunjung dapat mengakses berita atau kegiatan terbaru dari HI UNRAM.

b. Pengunjung dapat mengunduh file - file penting yang dikeluarkan oleh HI UNRAM.

c. Pengunjung dapat mengetahui profil dan kontak beserta informasi terkait akademik dari HI UNRAM.

d. Pengunjung dapat mengakses galeri foto yang telah di publikasi oleh HI UNRAM.

e. Pengunjung dapat mengetahui HMHI UNRAM melalui link eksternal yang ada di website HI UNRAM.

f. Pengunjung dapat melihat jumlah pengunjung yang sudah mengunjungi website HI UNRAM.

g. Pengunjung dapat mengetahui IJPSS HI UNRAM yang ada di website HI UNRAM

\subsubsection{Analisa Kebutuhan Admin}

a. Admin dapat melakukan login ke dashboard panel atau halaman mengelola website.

b. Admin dapat memahami proses menambahkan halaman website.

c. Admin dapat memahami proses memasukan file ke dalam website.

d. Admin dapat memahami proses megelola menu beserta tampilan website.

Berikut adalah tampilan website sebelum dikembangkan, yaitu bagian-bagian mana yang perlu dilakukan perbaikan sesuai dengan Analisa UCD yang dilakukan :

1. Dashboard

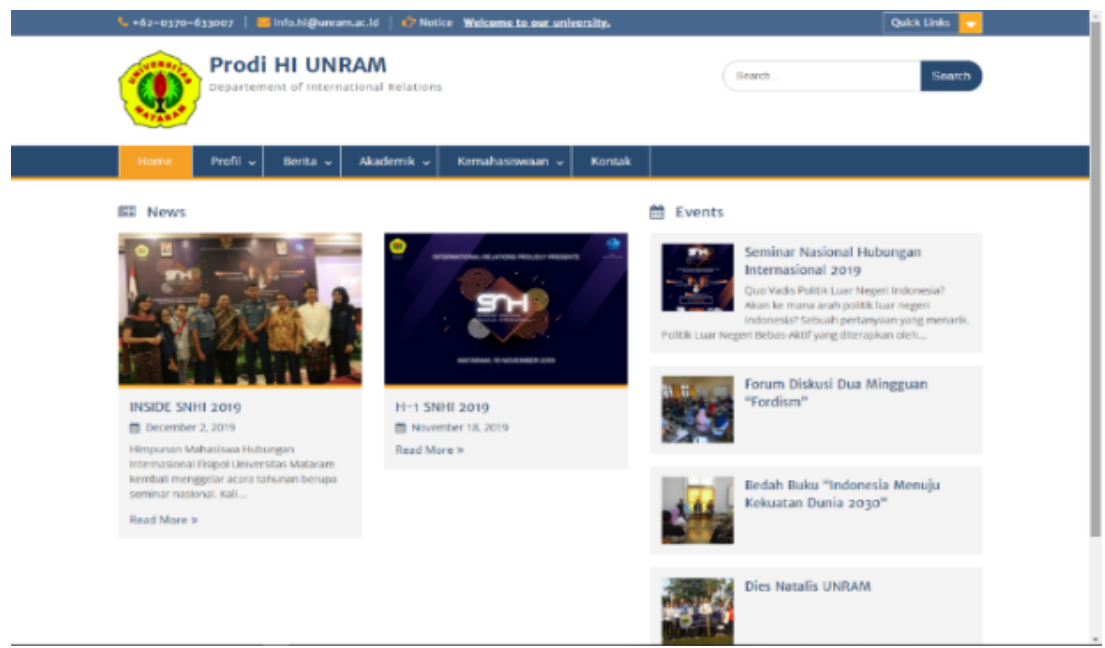

Gambar 2. Dashboard utama sebelum dikembangkan.

Pada gambar 2 merupakan tampilan dashboard sebelum dikembangkan, sesuai dengan analisis kebutuhan. Ditambahkan slider yang dapat membantu pengguna untuk mendapatkan informasi yang ingin ditampilkan oleh prodi HI UNRAM.

2. Dosen Pengajar

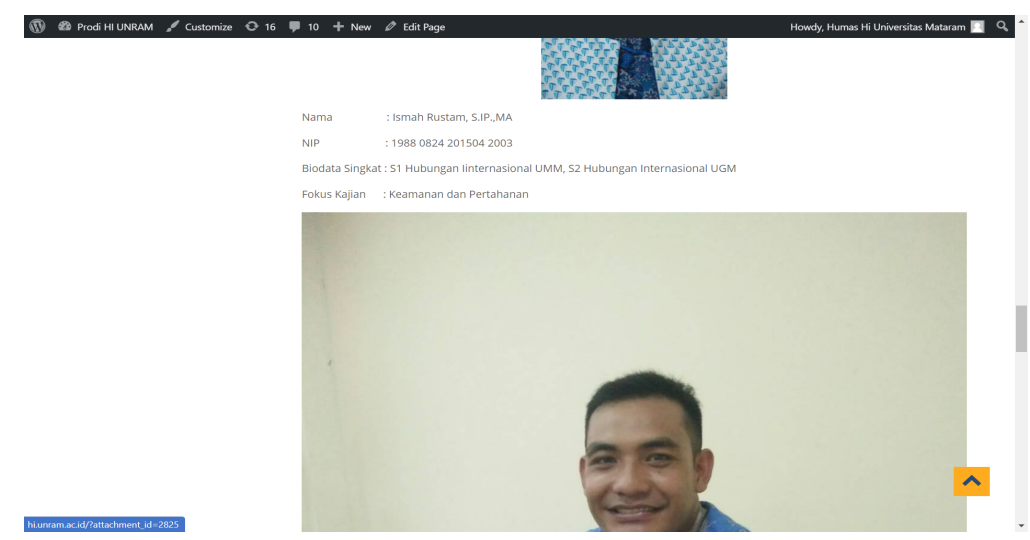

Gambar 3. Tampilan halaman dosen sebelum dikembangkan. 
Pada gambar 3 merupakan tampilan halaman dosen pengajar, pada halaman tersebut masih banyak gambar yang tidak seragam, dan informasi yang ditampilkan kurang informatif dilihat dari format penulisan yang tidak seragam.

3. Struktur Organisasi

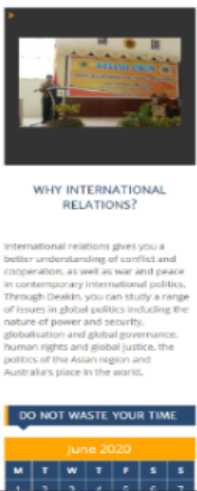

Struktur Organisasi

a sor

Gambar 4. Tampilan halaman struktur organiasasi sebelum dikembangkan.

Pada gambar 4 merupakan tampilan halaman strukrur organisasi sebelum dikembangkan, tampilan ini belum sama sekali ada isinya, hanya halaman kosong yang tidak memberikan informasi kepada pengguna terkait struktur organisasi.

\subsection{Solusi Perencanaan yang Dihasilkan (Produce Design Solution)}

Pada tahap ini akan dilakukan analisis design solution website yang merupakan solusi dari permasalahan yang ditemui. Analisis design solution terdiri dari tahapan - tahapan yaitu: 1. Use Case Diagram, 2. Activity Diagram, 3. Desain antar muka implementasi pengembangan website.

\subsubsection{Use Case Diagram}

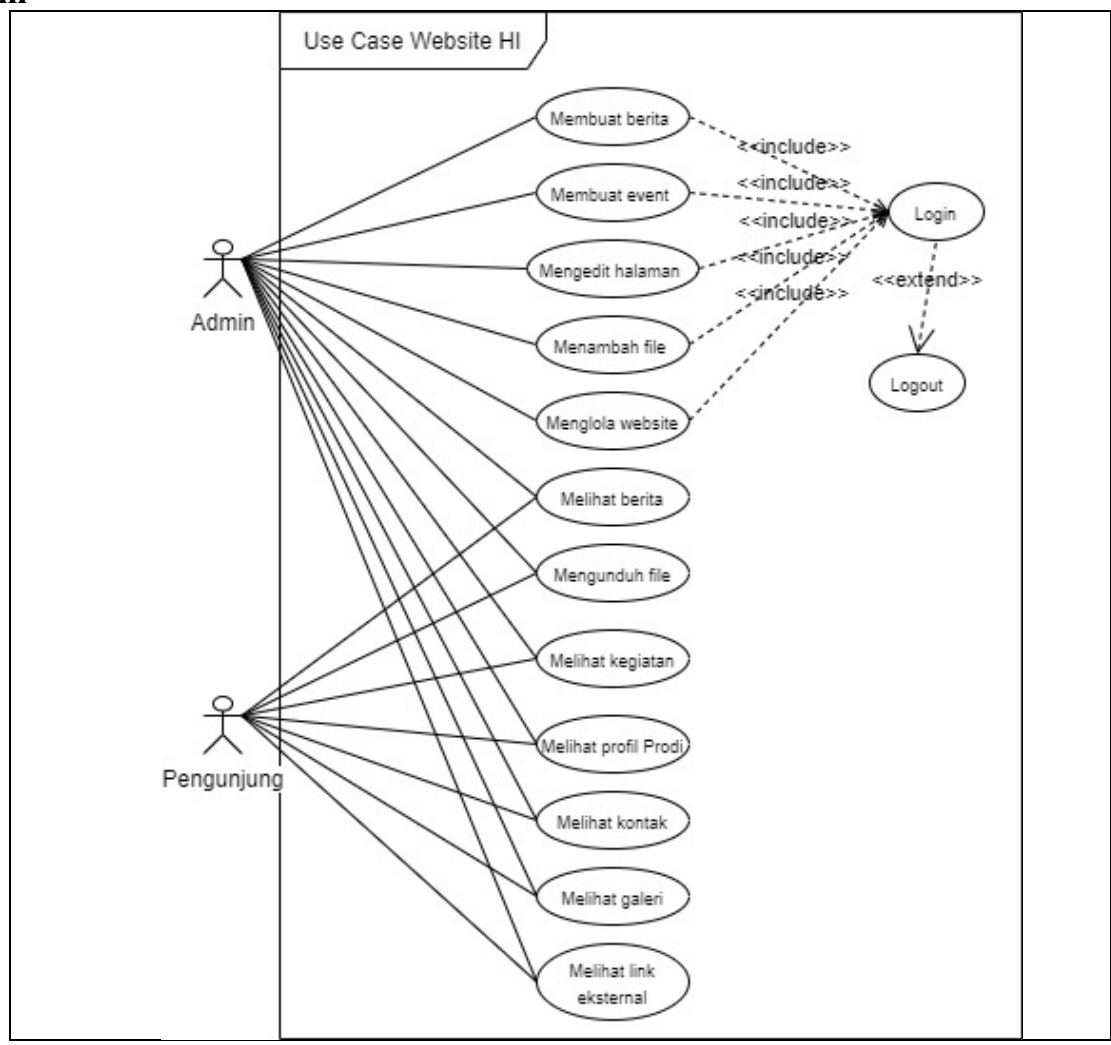

Gambar 5. Use Case Diagram.

Gambar 5 merupakan use case diagram dari website HI UNRAM, dalam use case tersebut terdapat dua actor yaitu admin dan pengunjung. 


\subsubsection{Desain Antar Muka Implementasi Pengembangan Website}

a. Dashboard utama.

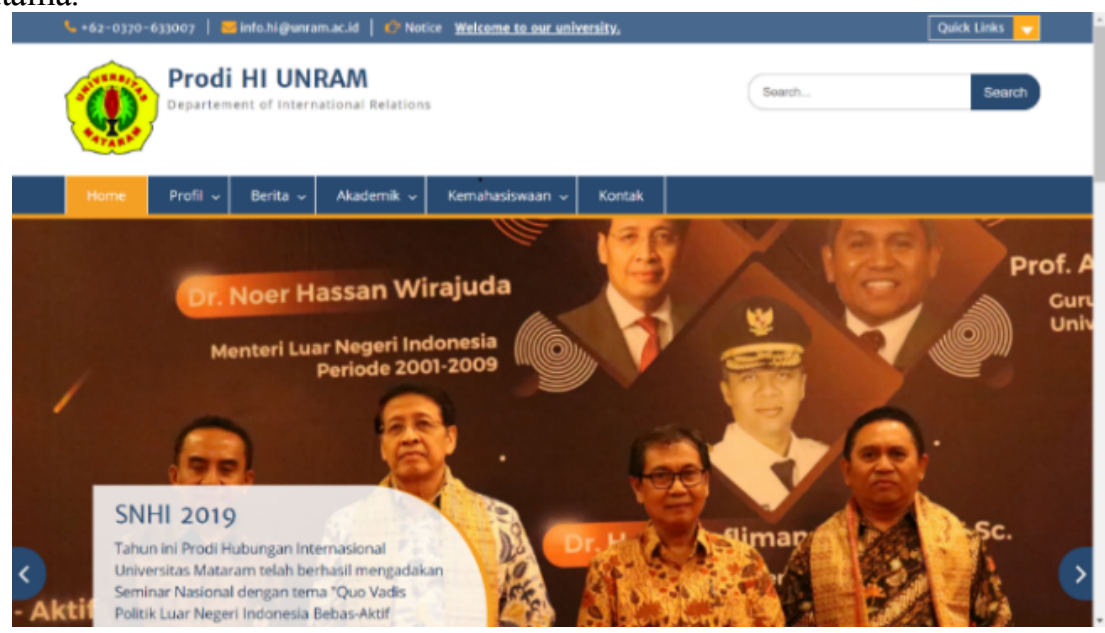

Gambar 6. Dashboard utama.

Pada Gambar 6 merupakan tampilan dashboard dengan ditambahkan slider untuk membantu memberikan update berita atau kegiatan terbaru yang diselenggarakan prodi hubungan internasional universitas mataram.

b. Tampilan halaman struktur organisasi.

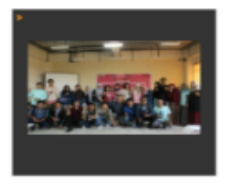

Struktur Organisasi
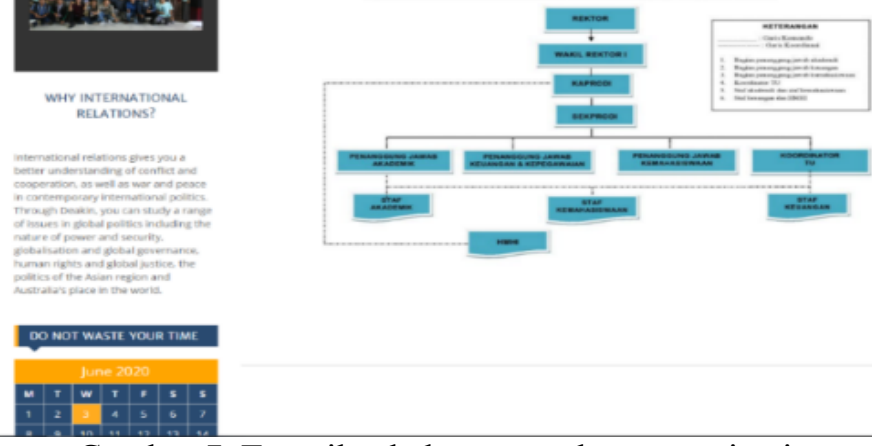

Gambar 7. Tampilan halaman struktur organisasi.

Pada Gambar 7 merupakan tampilan halaman strukrur organisasi, tampilan ini merupakan menu baru yang sebelumnya tidak ada. Pada halaman ini diberikan informasi yang ringkas berupa gambar struktur organisasi.

c. Tampilan plugin dan eksternal link.
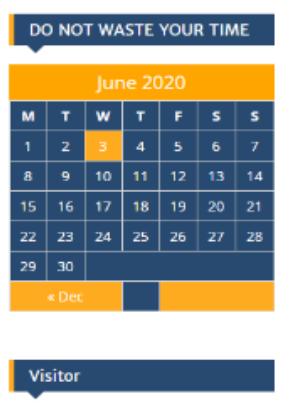

collaboration with :
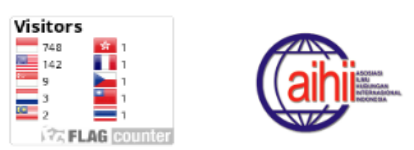

\section{ADps}

Gambar 8. Tampilan plugin dan eksternal link. 
Pada Gambar 8 merupakan tampilan plugin dan eksternal link, plugin ditambahkan sesuai dengan permintaan yaitu tanggalan dan jumlah pengunjung. Pengunjung diharapkan dapat melihat kegiatan terbaru dari tanggal dan melihat jumlah pengunjung yang telah melihat website, dan eksternal link berupa gambar dan link seperti persatuan HI nasional dan jurnal hubungan internasional universitas mataram.

\section{HASIL DAN PEMBAHASAN}

Sistem Informasi berbasis web pada Program Studi Hubungan Internasional Universitas Mataram Menggunakan Content Management System yang dibuat pada pengabdian masyarakat ini berjalan dengan baik sesuai dengan manfaat dan tujuan yang direncanakan. Setelah dilakukan tahap produce design solution untuk pembuatan sistem, tahap selanjutnya yaitu soaialisasi dan pelatihan serta evaluasi yang diuraikan masing-masing pada subbab berikut.

\subsection{Sosialisasi dan pelatihan website kepada dosen dan staf Program Studi Hubungan internasional}

a. Sosialisasi dan pelatihan website kepada dosen dan staf

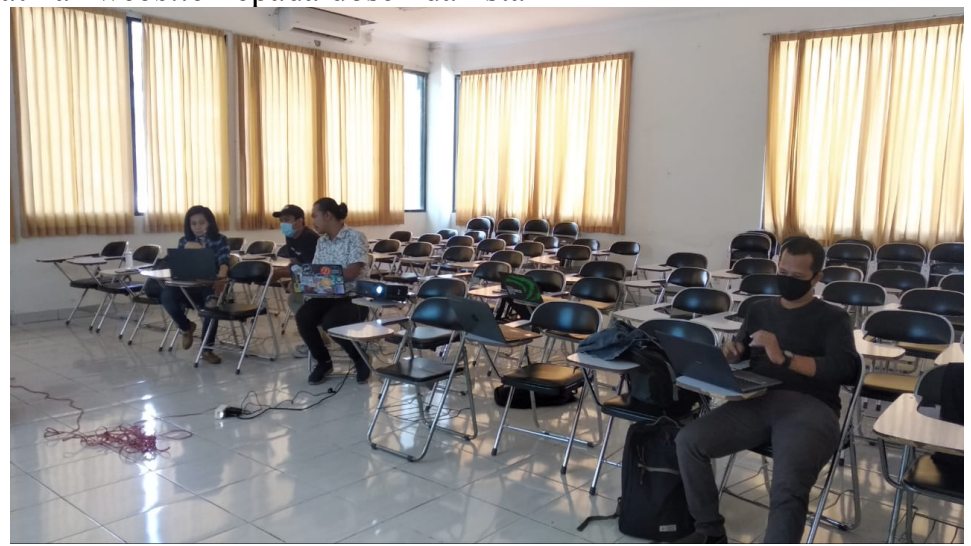

Gambar 9. Foto sosialisasi dan pelatihan website kepada dosen dan staf

Pada Gambar 9 merupakan highlight sesi sosialisasi dan pelatihan website, dalam sosialisasi dan pelatihan yang diadakan dihadiri oleh dosen pengajar dan staf tata kelola Program Studi Hubungan Internasional Universitas Mataram.

b. Pengisian post test evaluasi sosialisasi dan pelatihan kepada dosen dan mahasiswa

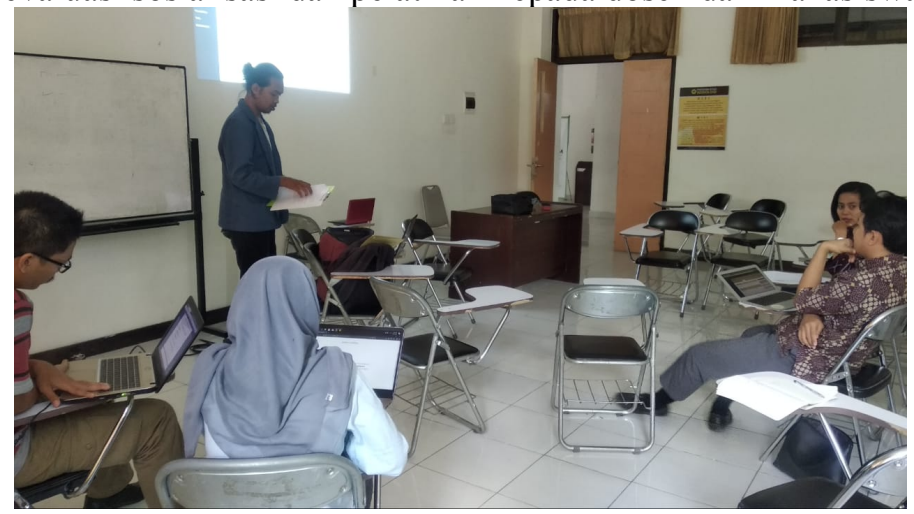

Gambar 10. Foto pengisian post test evaluasi sosialisasi dan pelatihan kepada dosen dan mahasiswa.

Pada Gambar 10 merupakan highlight sesi post test sosialisasi dan pelatihan website, dalam pengerjaan post test sosialisasi dan pelatihan yang diadakan dihadiri oleh dosen pengajar dan perwakilan mahasiswa Program Studi Hubungan Internasional Universitas Mataram.

\subsection{Evaluasi Perancangan Terhadap Kebutuhan Pengguna (Evaluate Designs Against User)}

Pada tahap ini akan dilakukan pengujian dengan metode kuisoner menggunakan google form yang targetnya adalah mahasiswa dan admin prodi hubungan internasional universitas mataram. Berikut adalah hasil dari kuisoner 
yang ditampilkan menggunakan pie chart atau diagram lingkaran dengan responden sebanyak 44 mahasiswa aktif dan 2 admin prodi hubungan internasional universitas mataram.

\subsubsection{Pengujian laman artikel berita dan kegiatan}

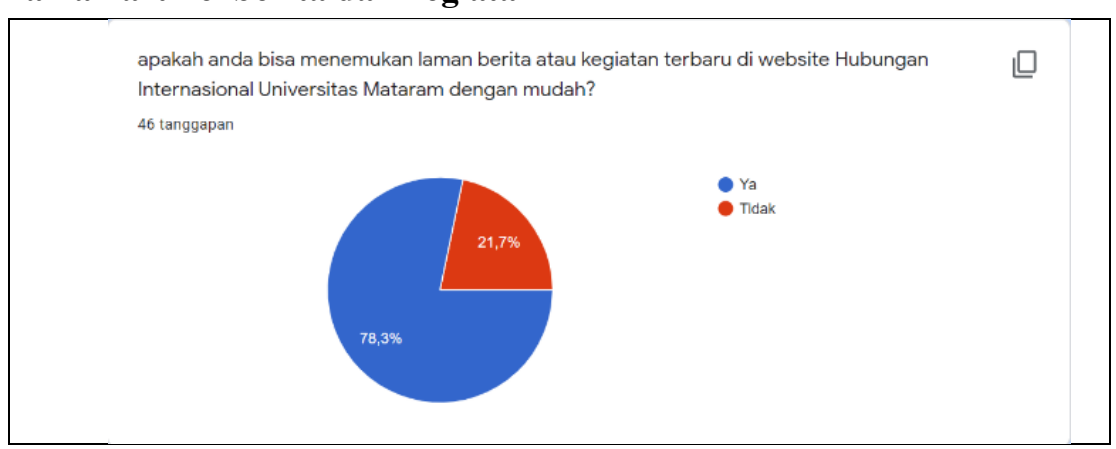

Gambar 11. Hasil responden penjujian laman artikel berita dan kegiatan.

Dilihat dari diagram lingkaran didapatkan persentase sebesar $78.3 \%$ untuk jawaban iya dan $21.7 \%$ untuk jawaban tidak, dari hasil tersebut dapat disimpulkan bahwa responden dapat menemukan laman berita atau kegiatan terbaru di website dengan mudah dibuktikan dengan persentase sebesar $78.3 \%$.

\subsubsection{Pengujian fitur unduh file penting}

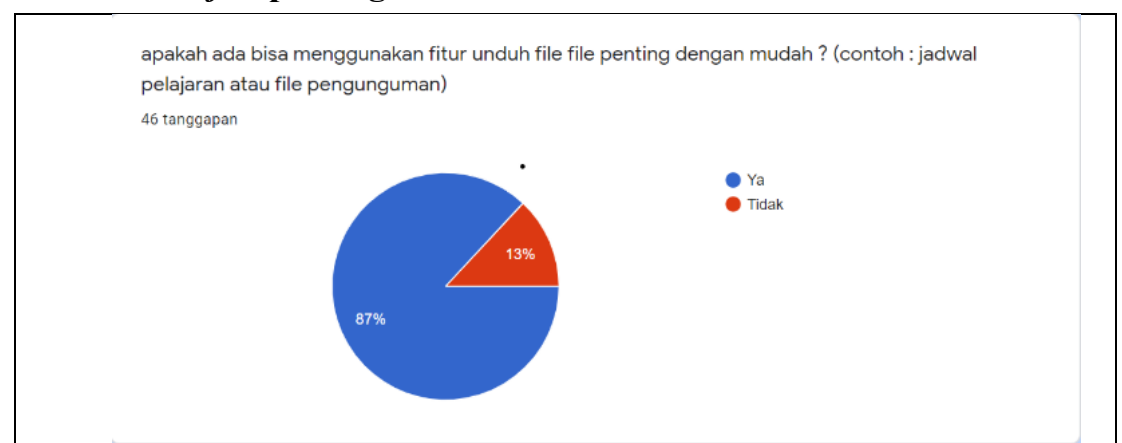

Gambar 12. Hasil responden fitur unduh file penting.

Dilihat dari diagram lingkaran didapatkan persentase sebesar $87 \%$ untuk jawaban iya dan $13 \%$ untuk jawaban tidak, dari hasil tersebut dapat disimpulkan bahwa responden dapat menggunakan fitur unduh file - file penting di website dengan mudah dibuktikan dengan persentase sebesar $87 \%$.

\subsubsection{Pengujian tampilan informasi profil prodi dan staf dosen}

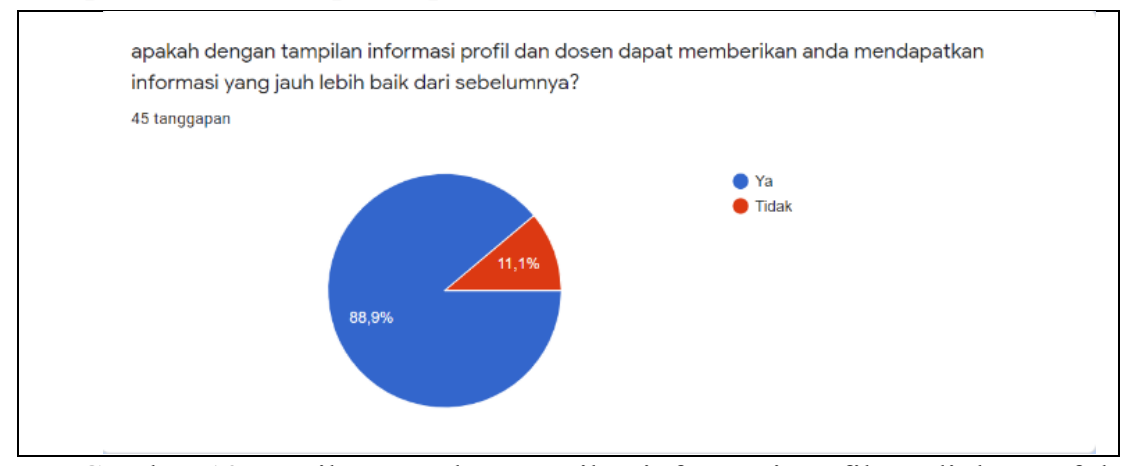

Gambar 13. Hasil responden tampilan informasi profil prodi dan staf dosen.

Dilihat dari diagram lingkaran didapatkan persentase sebesar $88.9 \%$ untuk jawaban iya dan $11.1 \%$ untuk jawaban tidak, dari hasil tersebut dapat disimpulkan bahwa responden mendapatkan informasi yang jauh lebih baik dari sebelumnya dibuktikan dengan persentase sebesar $88.9 \%$. 


\subsubsection{Pengujian sosialisasi membuat dan mengelola artikel website}

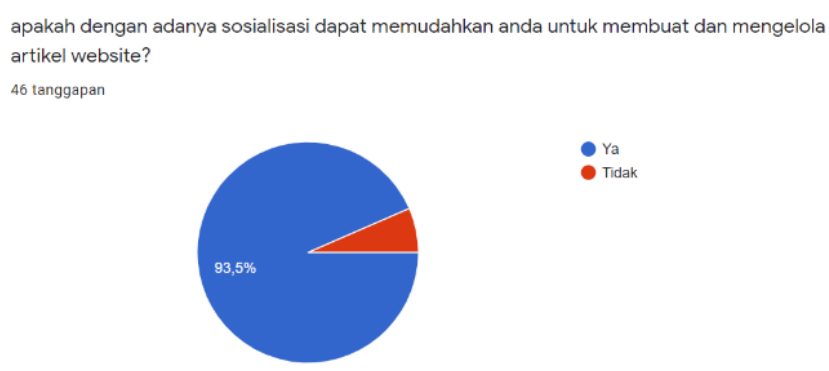

Gambar 14. Hasil responden pengujian sosialisasi membuat dan mengelola article website.

Dilihat dari diagram lingkaran didapatkan persentase sebesar $93.5 \%$ untuk jawaban iya dan $6.5 \%$ untuk jawaban tidak, dari hasil tersebut dapat disimpulkan bahwa responden dapat memahami dengan baik hasil dari sosialisasi membuat artikel dan mengelola website yang dibuktikan dengan persentase sebesar $93.5 \%$.

\subsubsection{Pengujian sosialisasi mengatur tata letak dan tampilan website}

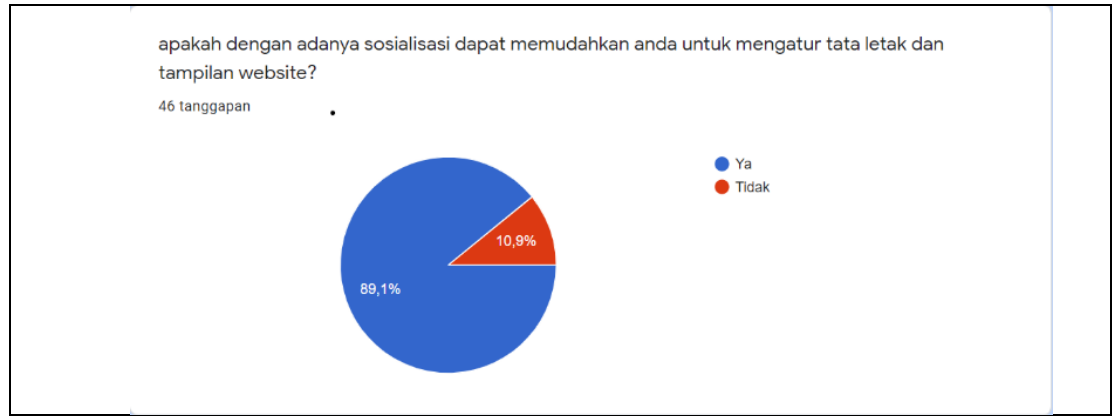

Gambar 15. Hasil responden pengujian sosialisasi mengatur tata letak dan tampilan website.

Dilihat dari diagram lingkaran didapatkan persentase sebesar $89.1 \%$ untuk jawaban iya dan $10.9 \%$ untuk jawaban tidak, dari hasil tersebut dapat disimpulkan bahwa responden dapat memahami dengan baik hasil dari sosialisasi mengatur tata letak dan tampilan website yang dibuktikan dengan persentase sebesar $89.1 \%$.

\subsubsection{Pengujian sosialisasi memasukan file penting atau gambar di website}

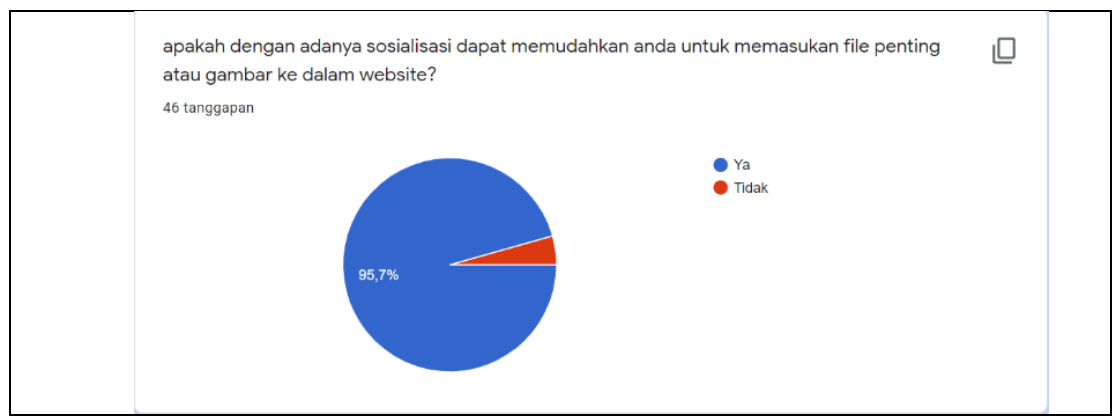

Gambar 16. Hasil responden pengujian sosialisasi memasukan file atau gambar di website.

Dilihat dari diagram lingkaran didapatkan persentase sebesar $95.7 \%$ untuk jawaban iya dan $4.3 \%$ untuk jawaban tidak, dari hasil tersebut dapat disimpulkan bahwa responden dapat memahami dengan baik hasil dari sosialisasi memasukan file penting atau gambar ke dalam website yang dibuktikan dengan persentase sebesar 95.7 $\%$.

Pengujian sistem dilakukan dengan metode MOS (Mean Opinion Score) untuk mengetahui respon dari responden pada sistem yang telah dibuat. Pengujian dilakukan untuk mengetahui kepuasan dari Program Studi Hubungan Internasional Universitas Mataram. Pengujian dilakukan dengan memberikan kuisoner kepada PRODI HI dengan menggunakan google form sebagai media untuk menjawab pertanyaan pada kuisoner yang diberikan. Pengujian dilakukan kepada 42 mahasiswa dan 2 admin. 
Hasil rekapitulasi jawaban responden dihitung dari jawaban berdasarkan pengisian kuesioner dari masingmasing pernyataan. Hasil rekapitulasi dihitung dengan mencari nilai rata-rata dari hasil respon masing-masing pertanyaan.

\begin{tabular}{|c|c|}
\hline Respon & Value \\
\hline Respon I & $78.3 \%$ \\
\hline Respon II & $87 \%$ \\
\hline Respon III & $88.9 \%$ \\
\hline Respon IV & $93.5 \%$ \\
\hline Respon V & $89.1 \%$ \\
\hline Respon VI & $95.7 \%$ \\
\hline Respon VII & $95.7 \%$ \\
\hline Total Mean & $\mathbf{8 9 . 7 4 \%}$ \\
\hline
\end{tabular}

Tabel 1. Hasil responden kuisoner.

Dapat disimpulkan dengan nilai total sebesar $89.74 \%$ untuk setuju bahwa pengembangan yang dilakukan diterima dengan baik.

\subsection{Kesimpulan}

\section{KESIMPULAN DAN SARAN}

Berdasarkan hasil pengabdian masyarakat di Program Studi Hubungan Internasional berupa sistem informasi bebrbasis web menggunakan wordpress, maka didapatkan kesimpulan sebagai berikut:

1. Dengan adanya pengembangan sistem informasi dengan menggunakan metode UCD didapatkan hasil berupa perancangan website dengan berpusat pada pengguna sehingga menghasilkan desain yang memudahkan pemohon untuk memberikan informasi yang lebih baik, seperti laman artikel, laman profil, laman dosen dan staf, laman kontak yang sudah dikembangkan sesuai dengan analisis kebutuhan.

2. Hasil dari sosilasisasi dan pelatihan kepada mahasiswa dan dosen Pogram Studi Hubungan Internasional Universitas Mataram didapatkan hasil yang mudah dimengerti dan dapat diimplementasikan dilihat dari hasil Mean Opinion Score (MOS) dengan rata-rata pemahaman diatas $89.74 \%$

\subsection{Saran}

Adapun saran yang dapat diberikan penulis agar website ini menjadi lebih baik di masa mendatang yaitu dalam pengembangan selanjutnya diharapkan website tersebut dapat diberikan plugin yang dapat mempermudah pengguna serta diberikan tampilan yang banyak mengimplementasikan javascript agar tampilan lebih aplikatif.

\section{Daftar Pustaka}

[1] B. Uno, Hamzah.H, Teknologi Komunikasi dan Informasi Pembelajaran, Bumi aksara, Jakarta, 2010.

[2] P. Hidayattullah, "Pemrograman Web," Bandung: Informatika Bandung, 2014.

[3] L. K. Scott, "Perancangan Dan Pembuatan Content Managemen System (Cms) 'Barca Cms' Menggunakan Framework Codeigniter," vol. 13, no. 3, 2013.

[4] D. Wijaya, "Content Management System,” vol. 20, no. 1, 2009.

[5] Gita Oktavianti, "Pengantar Sistem Informasi," Pengantar Sist. Inf., vol. 2, no. March, p. 31, 2019, [Online]. Available: https://www.researchgate.net/publication/331672535.

[6] Asriyanik, "Penilaian Keamanan Sistem Informasi Akademik Universitas Muhammadiyah Sukabumi Dengan Menggunakan ISO 27001,” J. Ilm. Sains dan Teknol., vol. 6, no. 2, pp. 501-506, 2016.

[7] Pratiwi, Dini. 2017. "Penggunaan Metode User Centered Design (UCD) Dalam Perancangan Ulang Web Portal Jurusan Psikologi FISIP Universitas Brawijaya.” Jurnal Pengembangan Teknologi Informasi dan Ilmu Komputer 2(7): 2448-58.

[8] Rohandi, Manda, Nurlaila Husain, and Indri W Bay. 2018. "Menggunakan User Centered Design.” Jnteti 7(1): 27-34.

[9] N. Aini, R. Ibnu Zainal, and A. Afriyudi, "Evaluasi Website Pemerintah Kota Prabumulih Melalui Pendekatan Website Usability Evaluation (Webuse),” J. Ilm. Betrik, vol. 10, no. 01, pp. 1-6, 2019, doi: 10.36050/betrik.v10i01.20.

[10] B. Irmawati, P. Studi, T. Informatika, F. Teknik, and U. Mataram, "The Analysis System Students Satisfaction Level Toward Teaching and Learning," vol. 1, no. 1, pp. 31-40, 2019. 